\title{
Predicting impacts of climate change on forest tree species of Bangladesh: evidence from threatened Dysoxylum binectariferum (Roxb.) Hook.f. ex Bedd. (Meliaceae)
}

\author{
Shawkat Islam Sohel ${ }^{(1)}$, \\ Sayma Akhter ${ }^{(2-6)}$, \\ Hadayet Ullah ${ }^{(3)}$, \\ Ekramul Haque $^{(4)}$, \\ Parvez Rana ${ }^{(6)}$
}

\begin{abstract}
The impact of climate change on ecosystems, especially at the species level, can be currently observed in many parts of the world. Species distribution models (SDMs) are widely used to predict the likely changes in the distribution of species in future climate change scenarios. The aim of the present study is to predict the effect of climate change on a valuable threatened tree species Dysoxylum binectariferum in the northeastern part of Bangladesh using the maximum entropy (MaxEnt) model on species' occurrence data. The future distribution of $D$. binectariferum was predicted under two scenarios from the IPCC $5^{\text {th }}$ assessment (RCP 4.5, and RCP 8.5) in 2050 and 2070. Model results showed that approximately $32 \%\left(2177 \mathrm{~km}^{2}\right)$ of the studied area is currently suitable for this species to grow. However, future predictions obtained by the model projected a complete loss of suitable habitat for $D$. binectariferum in the studied area by both 2050 and 2070 . Therefore, urgent measures are required for the conservation of $D$. binectariferum in northeastern Bangladesh. The application of species distribution models to simple inventory data (such as the occurrence of the species) may provide policymakers and conservationists with a useful tool for the prediction of future distribution (at both local and regional scales) of poorly known species with high preservation concerns.
\end{abstract}

Keywords: Habitat Distribution Modeling, Potential Distribution Areas, Reintroduction, MaxEnt, Conservation

\begin{abstract}
Introduction
The geographic distribution of a species is the geographic pattern of its occurrence across a territory and is highly influenced by geographic and environmental factors. Species distribution models (SDMs) can play a significant role in understanding the spatial/geographic pattern of species distribution. SDMs are based on the relationship between the presence records of species and environmental variables, including the climatic ones (Franklin 2009). These SDMs are widely used in diverse fields of research, such as biogeography, conserva-
\end{abstract}

tion biology, ecology, evolution, epidemiology, invasive species management, and other fields (Welk et al. 2002, Peterson \& Shaw 2003, Elith \& Leathwick 2009).

A number of species worldwide are currently affected by climate change, displaying accelerated changes such as habitat shift towards higher latitudes and altitudes (Parmesan \& Yohe 2003). In recent years, the importance of understanding the mechanism underlying climate-driven changes in species distribution has been discussed with high concern (Oliver et al. 2009). Climate change has already directly
(1) School of Agriculture and Food Science, The University of Queensland (Australia); (2) School of Environment, Natural Resources and Geography, Bangor University (UK); (3) School of Earth and Environmental Sciences, University of Adelaide (Australia); (4) Department of Forestry and Environmental Science, Shahjalal University of Science and Technology (Bangladesh); (5) School of Forest Sciences, University of Eastern Finland (Finland); (6) Faculty of Life Science, University of Copenhagen (Denmark)

@ Shawkat Islam Sohel (m.sohel@uq.edu.au)

Received: Feb 19, 2015 - Accepted: Jan 20, 2016

Citation: Sohel SI, Akhter S, Ullah H, Haque E, Rana P (2016). Predicting impacts of climate change on forest tree species of Bangladesh: evidence from threatened Dysoxylum binectariferum (Roxb.) Hook.f. ex Bedd. (Meliaceae). iForest 10: 154-160. - doi: 10.3832/ifor1608-009 [online 2016-05-25]

Communicated by: Rupert Seidl affected the distribution and phenology of many species (Lenoir et al. 2008). This is expected to result in some species being threatened, vulnerable, or even endangered (Thomas et al. 2004). Endangered tree species often play an important ecological role in forests, e.g., providing the habitat for many species (Yu et al. 2011). The number of endangered trees is reported to increase worldwide owing to climate change (Dawson et al. 2011). To sustainably manage landscape habitats and ecosystems, effective conservation strategies are to be enforced, and this must be done by taking into consideration the spatial pattern of occurrence of threatened species. Therefore, predicting species distribution has become an important part of conservation planning, and a number of SDMs have been developed to this purpose (Guisan \& Thuiller 2005).

Bangladesh has a unique assemblage of tropical tree species which are currently facing the threat of extinction owing to habitat loss. Climate change is likely to accelerate the process. Unfortunately, to the best of our knowledge, no study has evaluated the impact of climate change on the forest tree species of Bangladesh, and in particular on the distribution of threatened species. Recently, Alamgir et al. (2015) conducted a study on the potential effect of climate change on the habitat distribution of the Asian elephant and Hoo- 
lock gibbon in the Bangladesh forest ecosystems. According to the IUCN Red List, there are 106 threatened plant species in Bangladesh (Khan et al. 2001). Among these, D. binectariferum (Roxb.) Hook.f.ex Bedd., locally known as rata or rangi rata, grows in the semi-evergreen hilly forests of Bangladesh. This species is highly valued owing to the diversity of its uses. In a recent study, Jain et al. (2014) found that the bark of $D$. binectariferum could be a new source of anticancer drugs. However, no conservation efforts have been made over the years to protect this valuable resource. The main objective of this study is to assess the potential geographic distribution of $D$. binectariferum in future climate change scenarios. The results will be useful in planning conservation strategies, thereby enhancing the resilience of this threatened forest tree species to climate change.

\section{Materials and methods}

\section{Study area}

This study was conducted in the northeastern part of Bangladesh, a region that is experiencing an increasing trend of temperature and rainfall over time (Akhter et al. 2013). The area comprises two different districts (Moulvibazar and Habiganj), which are considered the major biodiversity hotspots of Bangladesh (Sohel et al. 2015), and include three protected areas currently managed under an Integrated Protected Area Co-management (IPAC) system: the Lawachara National Park, the Rema-Kalenga Wildlife Sanctuary, and the Satchari National Park (SNP - Fig. 1). Few scattered forest areas still exist adjacent to these protected areas.
In the Lawachara National Park, 167 plant species, 26 mammalian species (including 5 non-human primates), 246 bird species, 4 amphibian, and 6 reptile species have been recorded so far (NSP 2006). The forest is semi-evergreen (Craig 1991) with a canopy height varying from $10 \mathrm{~m}$ to $30 \mathrm{~m}$. The top canopy mainly comprises Tectona grandis, Artocarpus chaplasha, Tetrameles nudiflora, Hopea odorata, and Toona ciliata. The second canopy comprises Syzygium grande, Syzygium jambos, Syzygium cumini, Gmelina arborea, Ficus benghalensis, Dillenia pentagyna, Grewia asiatica, Ficus infectoria, and many more plant species. The understory includes Bambusa tulda, Alstonia scholaris, Eupatorium odoratum etc. together with several ferns and epiphytes (NACOM 2003). The original indigenous mixed tropical evergreen vegetation was logged in the 1920s. The soil of Lawachara is alluvial brown sandy clay loam to clay loam (NACOM 2003).

SNP has more than 200 plant species (NSP 2006). Acidic soils (sandy loam to silt clay) dominate this area and the relief is characterized by a gently undulating plain changing to a hilly topography. The prominent vegetation type in SNP is mixed tropical evergreen forest (Champion 1936). The relatively undisturbed forest is almost entirely restricted to the national park. At present, areas outside the reserved forest are being extensively converted into agricultural fields, fruit orchards, human settlements, sungrass (Saccharum spontaneum) fields including plantations of fast-growing timber species. Most plantations are dominated by exotic species such as Acacia spp., Eucalyptus camaldulensis, Tectona grandis, Albizia falcataria and Elaeis guineensis, forerunners of the palm oil industry in the

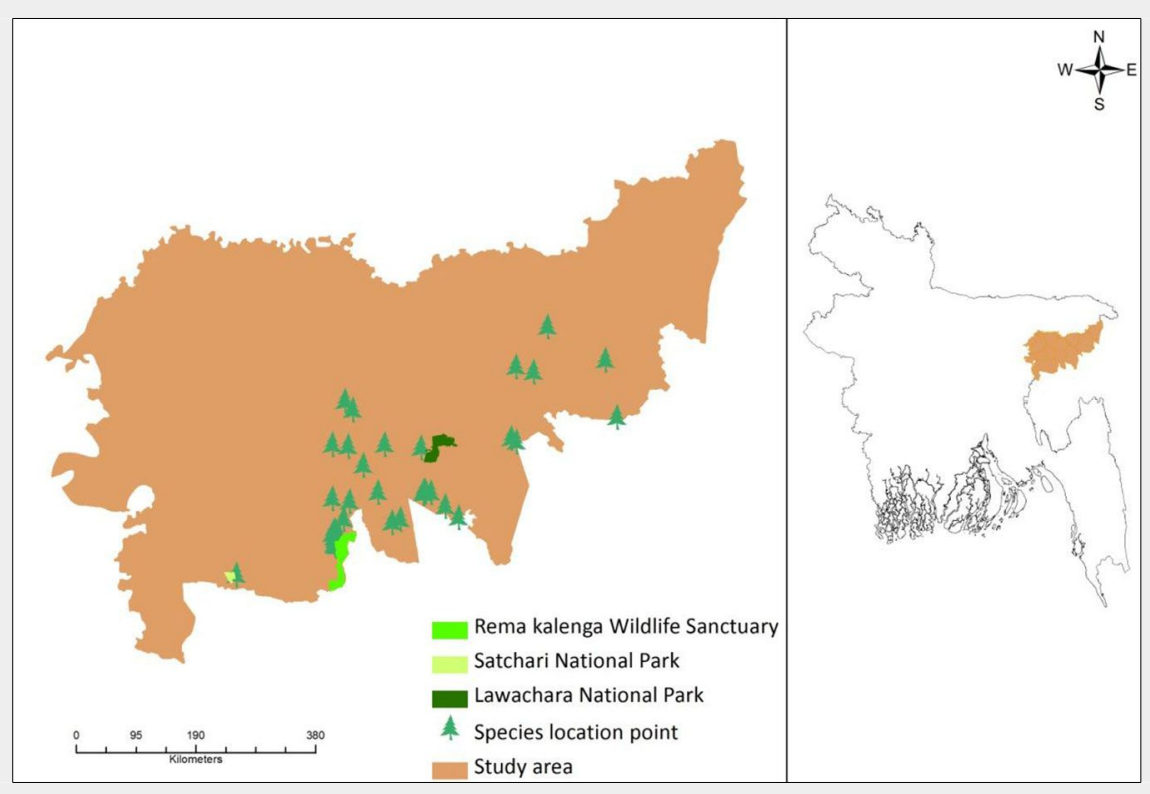

Fig. 1 - Map of the study area showing the D. binectariferum location points and the three protected areas inside the region (left panel). The geographic location of the area analyzed in this study (Moulvibazar and Habiganj districts) is also shown (right panel). country planted in this area during the midseventies (NSP 2006).

Rema-Kalenga wildlife sanctuary has 167 bird species, 37 species of mammals, and 638 plant species (NSP 2006). The soil texture is sandy loam to silty clay and acidic. The terrain of the national park is undulating with slopes and hillocks, locally called tila, ranging from $10-50 \mathrm{~m}$, scattered in the forest. The forest is drained by a number of small, sandy-bedded streams (NACOM 2003).

\section{Studied species and data collection}

The genus Dysoxylum includes approximately 80 species growing naturally in SE Asia, Southern China, New Guinea, Eastern and Northern Australia, New Caledonia, Fiji, and the Indian subcontinent (Sri Lanka, Bhutan, Nepal, India, and Bangladesh Peng \& Mabberley 2008). In Bangladesh, Dysoxylum binectariferum is a tree species growing up to $9 \mathrm{~m}$ in height, naturally distributed in semi-evergreen forests of hilly regions, and currently threatened by overexploitation. It is mostly used for building and furniture, and is considered an important source of Ayurvedic medicine in India, mainly for its use in treating rheumatism (Parcha et al. 2004). A recent study showed that $D$. binectariferum has anticancer treatment potential (Jain et al. 2014).

Data on the presence of $D$. binectariferum in the two aforementioned districts were collected by field surveys conducted in 2013-2014, totaling 69 records. Global Positioning System (GPS) was used to record the presence point in the field. The GPS coordinates were then converted to decimal degree format.

\section{Climate data}

Nineteen bioclimatic variables (Hijmans et al. 2005 - Tab. 1) with 30 -second ( $1 \mathrm{~km}$ ) spatial resolution were obtained from the WorldClim dataset (http://www.worldclim. com), and used to detect the most influential variables associated with the present and future distribution of $D$. binectariferum. Future climate scenario data for the years 2050 and 2070 (based on IPCC $5^{\text {th }}$ assessment data) were downloaded from the WorldClim dataset (http://www.worldclim. com), and used to project the potential distribution of the species under climate change. These data sets were downscaled and calibrated using WorldClim 1.4 as baseline "current" climate data. Two future greenhouse gas concentration trajectories, called as Representative Concentration Pathways (RCP) 4.5 and RCP 8.5 were selected for the periods 2050 and 2070, respectively. The RCP 4.5 is a relatively stable scenario where the total radiative forcing reaches $4.5 \mathrm{~W} \mathrm{~m}^{-2}$ by 2100 and further stabilises owing to the adoption of green technologies (Wise et al. 2009). Contrastingly, in RCP 8.5 emissions continue to increase throughout the $21^{\text {st }}$ century (Meinshausen et al. 2011). In this scenario, radia- 
tive forcing is predicted to reach up to 8.5 W $\mathrm{m}^{-2}$ by 2100 (Riahi et al. 2007). A Global Circulation Model (GCM), known as "Hadley Global Environment Model 2 Carbon Cycle" (HadGEM2-CC) and widely employed for simulating RCPs (Shrestha \& Bawa 2014), was used in this study. To reduce the influence of highly correlated variables, a multi-collinearity test was conducted to check cross-correlation among variables. Variables showing pairwise Pearson's correlation coefficient $|r| \geq 0.8$ were excluded from the analysis (Tab. 2). Based on such criterion, 14 bioclimatic variables were excluded and only 5 bioclimatic variables were used in the final model to predict the effect of climate change on the future distribution of $D$. binectariferum (Tab. 1).

\section{Prediction modeling}

For the prediction modeling, the maximum entropy (MaxEnt) model (Phillips et al. 2006) was chosen due to its better performance with small sample sizes as compare with other SDMs (Elith et al. 2006). The MaxEnt model uses presence-only data to predict species distribution based on the theory of maximum entropy (Phillips et al. 2006). A total of 500 runs were set for model building. For the studied species, $75 \%$ of the presence point data ( 52 points) was used to calibrate the model, while the remaining $25 \%$ (17 points) was used for validation purposes. The area under the curve (AUC) was used to assess the accuracy of the model. Generally, AUC values range from 0 to 1 . A high AUC value indicates that the model is performing well. The output from the model gave AUC values ranging from 0 to 1 , where 0 indicates a lower probability of distribution and 1 indicates a higher probability or suit-
Tab. 1 - List of the bioclimatic variables included in the initial and final MaxEnt model.

\begin{tabular}{|c|c|c|c|}
\hline \multirow{2}{*}{ Variable } & \multirow{2}{*}{ Description } & \multicolumn{2}{|c|}{ Final model } \\
\hline & & Yes & No \\
\hline $\mathrm{BIO1}$ & Annual Mean Temperature & - & - \\
\hline $\mathrm{BIO2}$ & Mean Diurnal Range (Mean of monthly max temp - min temp) & - & $x$ \\
\hline $\mathrm{BIO}$ & Isothermality (BIO2/BIO7) 100 & - & $x$ \\
\hline $\mathrm{BIO} 4$ & Temperature Seasonality (standard deviation $\cdot 100$ ) & - & $x$ \\
\hline $\mathrm{BIO5}$ & Max Temperature of Warmest Month & - & $x$ \\
\hline $\mathrm{BIO6}$ & Min Temperature of Coldest Month & - & $x$ \\
\hline $\mathrm{BIO7}$ & Temperature Annual Range (BIO5-BIO6) & $x$ & - \\
\hline $\mathrm{BIO8}$ & Mean Temperature of Wettest Quarter & - & $x$ \\
\hline $\mathrm{BIO9}$ & Mean Temperature of Driest Quarter & - & $x$ \\
\hline $\mathrm{BIO10}$ & Mean Temperature of Warmest Quarter & $x$ & - \\
\hline $\mathrm{BIO11}$ & Mean Temperature of Coldest Quarter & $x$ & $x$ \\
\hline $\mathrm{BIO12}$ & Annual Precipitation & - & $\mathrm{x}$ \\
\hline $\mathrm{BIO13}$ & Precipitation of Wettest Month & - & $\mathrm{x}$ \\
\hline $\mathrm{BIO14}$ & Precipitation of Driest Month & - & $x$ \\
\hline $\mathrm{BIO15}$ & Precipitation Seasonality (Coefficient of Variation) & $x$ & - \\
\hline $\mathrm{BIO} 16$ & Precipitation of Wettest Quarter & - & $x$ \\
\hline $\mathrm{BIO17}$ & Precipitation of Driest Quarter & $x$ & - \\
\hline $\mathrm{BIO18}$ & Precipitation of Warmest Quarter & - & $x$ \\
\hline $\mathrm{BIO19}$ & Precipitation of Coldest Quarter & - & $x$ \\
\hline
\end{tabular}

ability of distribution. To ensure the model's robustness, 3 replicated model trials were executed with a threshold rule of 10 percentile training presence; this means that $10 \%$ of each species records with the lowest predicted values will fall into the absence regions delineated by the model, while the presence regions will encompass the other $90 \%$ of records having the highest predicted values. The output distribution records of the MaxEnt model based on the AUC value were further classified into two groups of suitability: Not suitable ( $<25 \%$ of occurrence) and suitable ( $>25 \%$ of occurrence). The jackknife procedure of the MaxEnt model was used to find out which variables had the greatest influence.
Jackknife is a statistical estimator of a parameter obtained by systematically leaving out each observation from a dataset, calculating the estimate of the importance and then finding the average of those calculations (Efron \& Stein 1981). As MaxEnt is a presence/background point-based model, the maximum number of background points was set at 10,000 . As only presence data were provided in the model for the species studied (no absence data were available), using background points the model will assume that the species is equally likely to be found anywhere in the landscape analyzed. This means that every pixel has the same probability of being selected as background in the geographic

Tab. 2 - Pairwise correlation matrix (Pearson's correlation coefficients, $r$ ) between bioclimatic variables. Variables showing $|r| \geq 0.8$ were discarded from the analysis, and only $\mathrm{BIO} 7, \mathrm{BIO} 10, \mathrm{BIO} 11, \mathrm{BIO} 15, \mathrm{BIO} 17$ were included in the model.

\begin{tabular}{|c|c|c|c|c|c|c|c|c|c|c|c|c|c|c|c|c|c|c|c|}
\hline Variable & $\frac{a}{\circ}$ & $\frac{\overline{0}}{\infty}$ & 음 & $\stackrel{m}{0}$ & $\frac{\text { 음 }}{\infty}$ & 음 & 음 & 음 & $\stackrel{\infty}{\circ}$ & 음 & $\frac{ㅇ}{0}$ & $\frac{\bar{\sigma}}{\operatorname{co}}$ & $\frac{N}{0}$ & $\frac{m}{\circ}$ & $\frac{ \pm}{\operatorname{O}}$ & $\frac{\text { 음 }}{\frac{0}{\infty}}$ & $\frac{\circ}{\circ}$ & $\frac{1}{\circ}$ & $\frac{\infty}{\infty}$ \\
\hline $\mathrm{BIO19}$ & 1.00 & -0.66 & 0.04 & 0.95 & -0.45 & -0.92 & 0.24 & -0.65 & -0.83 & -0.06 & -0.58 & -0.06 & 0.77 & 0.69 & 0.72 & -0.25 & 0.73 & 1.00 & 0.70 \\
\hline BIO1 & - & 1.00 & -0.54 & -0.68 & -0.15 & 0.61 & 0.41 & 0.07 & 0.77 & 0.70 & 0.80 & 0.70 & -0.46 & -0.42 & -0.58 & 0.21 & -0.44 & -0.66 & -0.41 \\
\hline $\mathrm{BIO2}$ & - & - & 1.00 & 0.08 & 0.84 & 0.19 & -0.94 & 0.71 & -0.09 & -0.92 & -0.16 & -0.92 & -0.25 & -0.26 & 0.12 & -0.41 & -0.27 & 0.04 & -0.27 \\
\hline $\mathrm{BIO}$ & - & - & - & 1.00 & -0.42 & -0.93 & 0.21 & -0.63 & -0.81 & -0.10 & -0.56 & -0.10 & 0.81 & 0.74 & 0.73 & -0.16 & 0.78 & 0.95 & 0.74 \\
\hline $\mathrm{BIO}$ & - & - & - & - & 1.00 & 0.63 & -0.95 & 0.95 & 0.36 & -0.79 & 0.20 & -0.79 & -0.58 & -0.54 & -0.19 & -0.19 & -0.57 & -0.45 & -0.56 \\
\hline $\mathrm{BIO5}$ & - & - & - & - & - & 1.00 & -0.42 & 0.81 & 0.83 & -0.08 & 0.61 & -0.08 & -0.90 & -0.84 & -0.72 & -0.04 & -0.88 & -0.92 & -0.85 \\
\hline $\mathrm{BIO6}$ & - & - & - & - & - & - & 1.00 & -0.87 & -0.10 & 0.92 & 0.08 & 0.92 & 0.45 & 0.43 & 0.07 & 0.29 & 0.45 & 0.24 & 0.45 \\
\hline $\mathrm{BIO7}$ & - & - & - & - & - & - & - & 1.00 & 0.51 & -0.64 & 0.28 & -0.64 & -0.78 & -0.73 & -0.43 & -0.21 & -0.76 & -0.65 & -0.75 \\
\hline $\mathrm{BIO8}$ & - & - & - & - & - & - & - & - & 1.00 & 0.21 & 0.79 & 0.21 & -0.64 & -0.57 & -0.58 & 0.23 & -0.60 & -0.83 & -0.57 \\
\hline $\mathrm{BIO9}$ & - & - & - & - & - & - & - & - & - & 1.00 & 0.37 & $1.00^{*}$ & 0.15 & 0.14 & -0.20 & 0.26 & 0.15 & -0.06 & 0.17 \\
\hline $\mathrm{BIO10}$ & - & - & - & - & - & - & - & - & - & - & 1.00 & 0.37 & -0.34 & -0.29 & -0.30 & 0.27 & -0.32 & -0.58 & -0.31 \\
\hline BI011 & - & - & - & - & - & - & - & - & - & - & - & 1.00 & 0.15 & 0.14 & -0.20 & 0.26 & 0.15 & -0.06 & 0.17 \\
\hline $\mathrm{BIO12}$ & - & - & - & - & - & - & - & - & - & - & - & - & 1.00 & 0.99 & 0.85 & 0.38 & 1.00 & 0.77 & 0.96 \\
\hline $\mathrm{BIO13}$ & - & - & - & - & - & - & - & - & - & - & - & - & - & 1.00 & 0.85 & 0.50 & 1.00 & 0.69 & 0.96 \\
\hline $\mathrm{BIO} 14$ & - & - & - & - & - & - & - & - & - & - & - & - & - & - & 1.00 & 0.31 & 0.85 & 0.72 & 0.81 \\
\hline BI015 & - & - & - & - & - & - & - & - & - & - & - & - & - & - & - & 1.00 & 0.45 & -0.25 & 0.44 \\
\hline $\mathrm{BIO} 16$ & - & - & - & - & - & - & - & - & - & - & - & - & - & - & - & - & 1.00 & 0.73 & 0.96 \\
\hline $\mathrm{BIO17}$ & - & - & - & - & - & - & - & - & - & - & - & - & - & - & - & - & - & 1.00 & 0.70 \\
\hline $\mathrm{BIO18}$ & - & - & - & - & - & - & - & - & - & - & - & - & - & - & - & - & - & - & 1.00 \\
\hline
\end{tabular}


space; likewise, every environment has the same probability of being selected as background, according to its frequency in the environmental space (Phillips et al. 2009).

\section{Results}

The performance of the model applied was high, with a mean AUC value of 0.89 for the training and test dataset, indicating that the selected variables provided a satisfactory prediction of the distribution of this threatened tree species. Amongst the five bioclimatic input variables, annual temperature range $\left(\mathrm{BIO}_{7}\right)$ and mean temperature of coldest quarter (BIO11) were the two most influential factors that collectively contributed to $71.6 \%$ of the model's variance, followed by precipitation seasonality (BIO15). Precipitation in the driest quarter (BIO17) made the lowest contribution to the model. The Jackknife test showed that the mean temperature of the coldest quarter (BIO11) had the highest training gain when considered independently. However, the training gain decreased when precipitation seasonality
(BIO 15) was excluded from the model (Fig. 2).

The responses of the species to changes in bioclimatic variables are summarized in Fig. 3. Response curves were obtained by changing the value of each predictor variable while retaining all other variables at their average sample value. As displayed in Fig. 3, the distribution of $D$. binectariferum is highly controlled by both temperature and precipitation. Annual range of temperature $\left(\mathrm{BIO}_{7}\right)$ was used to examine whether species distribution was affected by different ranges of extreme temperature conditions. Indeed, the probability of presence of the species in the study area increased with increased annual range of temperature, and was found to be the highest between 23 and $25{ }^{\circ} \mathrm{C}$. Mean temperature of the warmest quarter (BIO10) provides the mean temperatures during the warmest three months of the year, which can be used for examining how such environmental factors affect the seasonal distribution of different species. In our case, $D$. binectariferum started declining when the tem- perature exceeded $27^{\circ} \mathrm{C}$ during the warmest month. Mean temperature of the coldest quarter (BIO11) provides the mean temperatures during the three coldest months of the year. The probability of the presence of the studied species was high in areas where winter temperature is around $18{ }^{\circ} \mathrm{C}$. Contrastingly, D. binectariferum showed a declining trend at temperatures higher than $18^{\circ} \mathrm{C}$. Precipitation seasonality (BIO15) reflects the rainfall variability, with larger percentages representing a greater variability in precipitation. Based on our results, the studied species was unable to tolerate higher variability (>78\%) of rainfall. Furthermore, precipitation of the driest quarter (BIO17) represents the total precipitation during the driest three months of the year. As for this variable, D. binectariferum showed a higher probability of presence in areas characterized by a dry season with rainfall between 40 and $50 \mathrm{~mm}$ (Fig. 3).

The potential current distribution of $D$. binectariferum predicted by the MaxEnt model is shown in Fig. 4. Based on model's

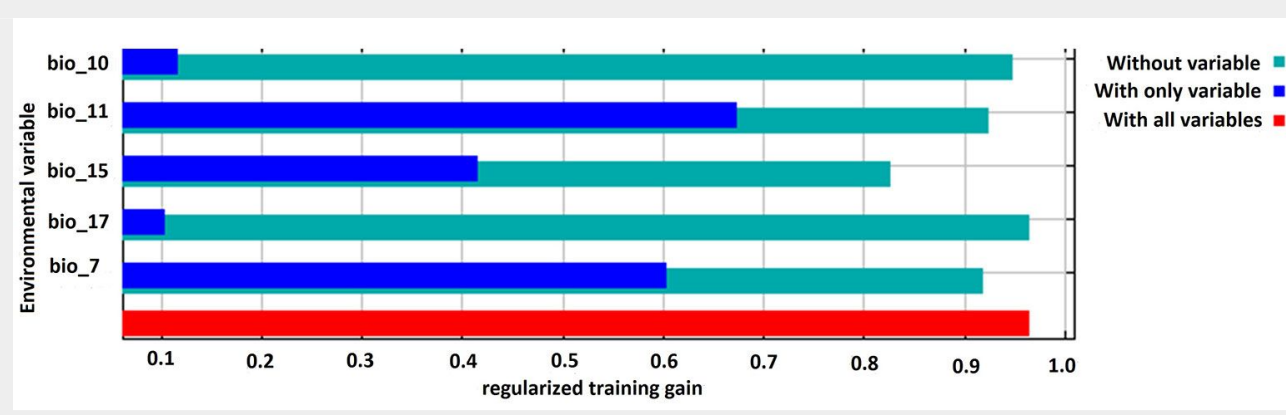

Fig. 2 - Result of the jackknife test for assessing the relative contribution of the environmental variables used as predictors to the habitat model. (BIO10): Mean temperature of warmest quarter; (BIO11): mean temperature of coldest quarter; (BIO15): precipitation seasonality; (BIO17): precipitation of driest quarter; (BIO7): temperature annual range.
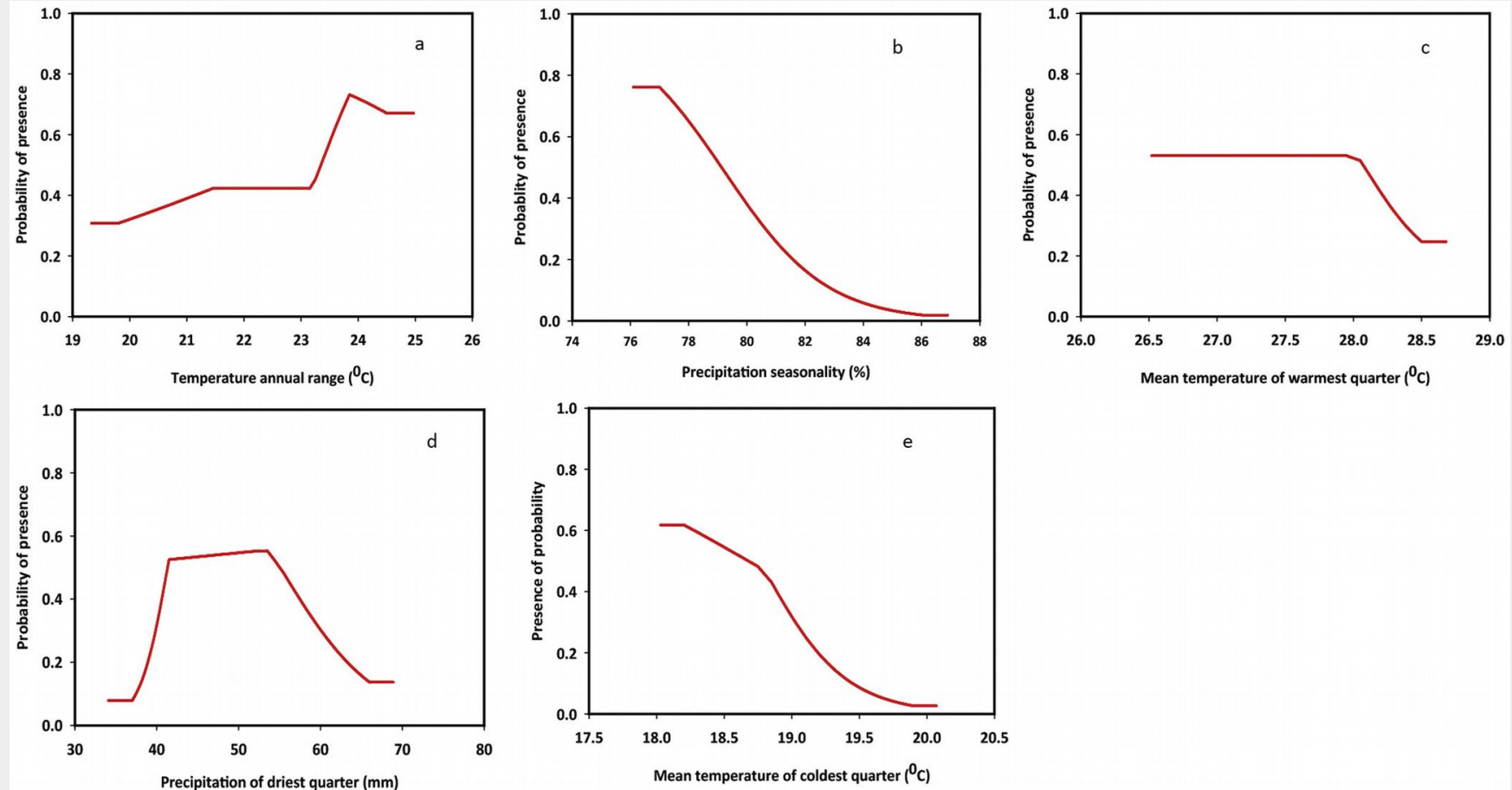

Fig. 3 - Response curves of bioclimatic variables from the MaxEnt model. (a) Temperature annual range; (b) precipitation seasonal ity; (c) mean temperature of warmest quarter; (d) precipitation of driest quarter; (e) mean temperature of coldest quarter. 
Fig. 4 - Current potential distribution of Dysoxylum binectariferum in the northeastern part of Bangladesh as predicted by the MaxEnt model applied to preslocation of the area analyzed in this study (Moulvibazar and Habiganj districts) is shown in orange (right panel). ence data (left panel). The geographic

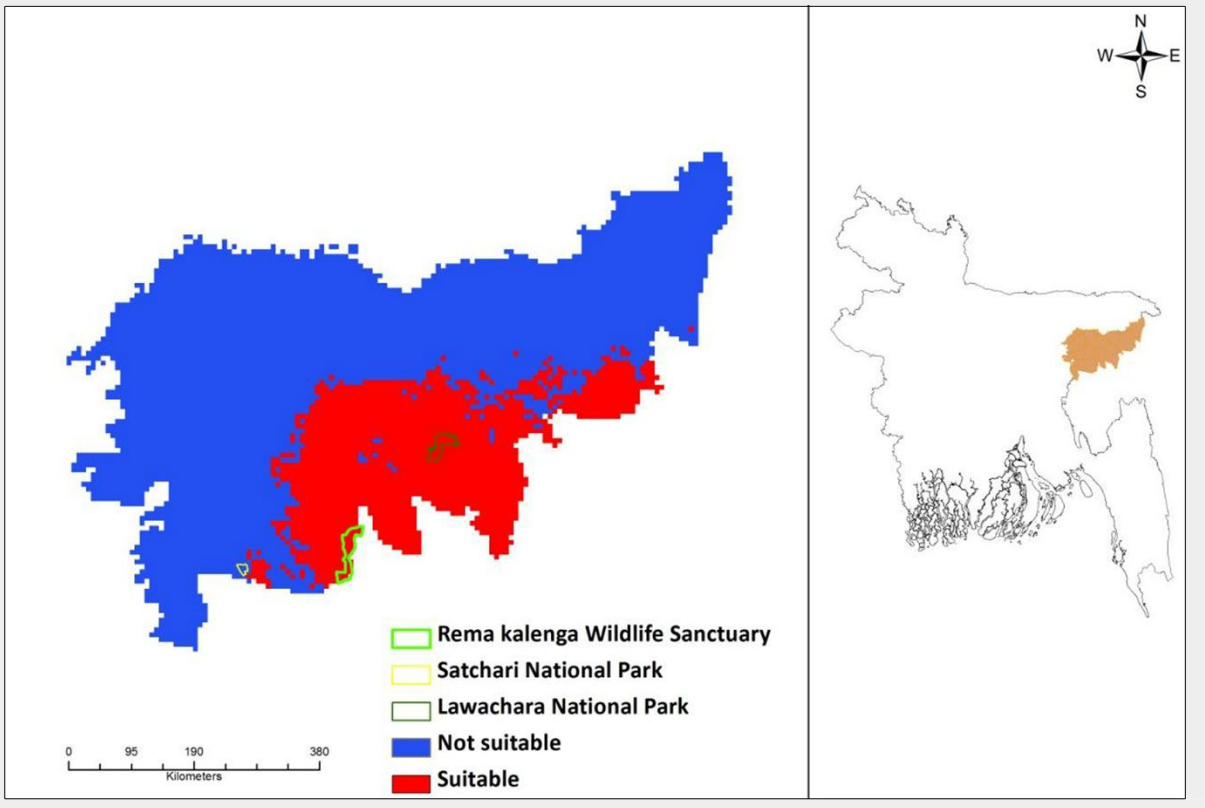

Fig. 5 - Complete loss of habitat in predicted future distribution of Dysoxylum binectariferum in northeastern Bangladesh under climate change scenarios RCP4.5 (2050), RCP4.5 (2070), RCP8.4 (2050), RCP8.4 (2070), as projected by the MaxEnt model applied to presence data (left panel). The geographic location of the area analyzed in this study (Moulvibazar and Habiganj districts) is shown in orange (right panel). predictions, about $2177 \mathrm{~km}^{2}$ (32\%) of the studied area is currently suitable for this species. By overlaying the maps of the three protected areas (Lawachara National Park, Satchari National Park, and RemaKalenga Wildlife Sanctuary) on the district map, it may be easily noticed that the species is mostly located in and around these protected areas. Considering the impact of climate change on this species, the predicted distribution under IPCC future climate scenarios (RCP4.5 and RCP 8.5 ) in 2050 and 2070 suggests a complete loss of suitable habitats for the species (Fig. 5).

\section{Discussion and conclusions}

Conservation activities in most tropical regions have often failed owing to a lack of proper knowledge of the target species in terms of habitat suitability. The application of species distribution models (SDMs) to simple inventory data (such as the presence of a species) may provide policymakers and conservationists with predictions of future distribution of the target species at both local and regional scales. This will in turn lead to an improved understanding of the factors influencing species distribution in the light of climate change (Gray et al. 2007). In this study, we showed the effectiveness of such habitat suitability models for the conservation of poorly known species by providing important information about local distribution and habitat preference, subject to climate change. An intricate relationship between forests and climate change was observed at a global scale (Karjalainen et al. 2010). SDMs have been proven to be important tools in assessing the distribution and potential relationship between species and bioclimatic variables (Wiens et al. 2009). In the last decade, several studies have been con- ducted on the effects of climate change on forests and ecosystems (Wiens et al. 2009, Barrows et al. 2010). These authors demonstrated that climate change affects forests species and hypothesized that the rate of future climate change may lead to a mass extinction of species, with a consequent forest habitat degradation or loss. The results of this study support the findings of previous studies mentioned above. Indeed, modeling results showed that the suitable habitats of $D$. binectariferum are likely to be reduced or loss under future climate change scenarios. On a regional scale, Bangladesh has already experienced substantial changes in its forest ecosystem and is highly susceptible to any future changes owing to its particular geo-climatic location. For example, Alamgir et al. (2015) concluded that the habitat of Asian elephant is expected to remain constant (i.e., 38\%) throughout 2050 and 2070, whilst the habi- 
tat of the Hoolock gibbon will be reduced between $82 \%$ and $100 \%$ under the IPCC climate change scenario. Furthermore, Trisurat et al. (2011) found that approximately 31 tree species will lose their suitable habitat by 2100 in southeastern Asia. Bakkenes et al. (2002) found that more than $16 \%$ of European land area is likely to face local species loss that may exceed $50 \%$ by 2050 . Studies have shown that climate change may also directly or indirectly affect endangered or rare tree species in different ways, including decline in numbers, genetic loss, and even extinction (Dawson et al. 2011, Dullinger et al. 2012).

In this Anthropocene era, humans are intensely altering the environments of plants and wildlife. Forest loss and degradation will significantly affect plant habitats in terms of size and quality, and this trend is expected to persist in the future (Feeley \& Silman 2010). Illegal logging, encroachment and forest clearance are predominantly responsible for habitat destruction in most tropical forest areas (Sohel et al. 2010). Conservation of habitats is the most effective action of biodiversity conservation, thereby helping prevent extinction of species. Currently, forests are facing rapid reduction due to the increased rate of land-use change, mainly for agricultural purposes. Such changes are also taking place in the study area, threatening the existence of $D$. binectariferum. The livelihood of the people living near the forest at the study site is highly dependent on forest resources, e.g., via illegal logging (Akhter et al. 2013). Indeed, D. binectariferum has high timber value which makes it an attractive source of income through illegal logging, directly resulting in its status of threatened species. Such increasing habitat degradation calls for new approaches aimed to gain an insight into species distribution. The combined effect of climate change and and habitat destruction could not be investigated in the present study owing to a lack of data.

The findings of this study can be considered as crucial information regarding climate change research on the forest species of Bangladesh. The approach used in this study can be applied to other tree species with high preservation concerns. The results may provide useful guidelines for government and non-government organisations who are responsible for the conservation and management of forest resources. Nevertheless, this study has some limitations. For instance, the choice of the SDM and emission scenarios can lead to overestimation or underestimation of the future distribution of the selected species. Therefore, we recommend the MaxEnt model used in this study to be used in conjunction with other SDMs and emissions scenarios. Nonetheless, we consider the results of this empirical study as an early warning of the effect of climate change on the future distribution of endangered species, which may help conservation man- agers in designing policies that may reduce the vulnerability of threatened or rare tree species.

Protection of threatened or rare species is unfeasible without the protection of their habitats. Protection of a forest habitat can be undertaken using different approaches. Apart from establishing protected or reserve areas, landscape connectivity between non-protected areas should also be taken into account. To this purpose, the addition of new areas seems to be an effective approach (Hannah et al. 2002). Additionally, the active participation of the local, forest-dependent people is fundamental, especially in developing countries, as successful forest conservation is not possible without their active participation (Sohel et al. 2010). To engage the local people in the decision-making process of conserving forests, a participatory approach or co-management system should be introduced. The Government of Bangladesh has prioritized the above-mentioned issues, so most of the protected areas of Bangladesh are now under a comanagement system. Finally, an awareness programme should also be prioritized to address climate change issues and protect the valuable forest resources of Bangladesh for future generations.

\section{Acknowledgements}

We acknowledge the support from the Forest Department staff of the Sylhet Forest Division of Bangladesh during tree location searching. We are grateful to two anonymous reviewers for their useful comments and feedback that improved the quality of the paper. Special thanks to Nerys Lloyd Mullally, Bangor University, UK for editing the manuscript.

\section{References}

Akhter S, Raihan F, Sohel MSI, Syed MA, Das SK, Alamgir M (2013). Coping with climate change by using indigenous knowledge of ethnic communities from in and around Lawachara National Park of Bangladesh. Journal of Forest Science 29: 181-193. - doi: 10.7747/JFS.2013.29.3.181 Alamgir M, Mukul SA, Turton SM (2015). Modelling spatial distribution of critically endangered Asian elephant and Hoolock gibbon in Bangladesh forest ecosystems under a changing climate. Applied Geography 60: 10-19. - doi: 10.1016/j.apgeog.2015.03.001

Bakkenes M, Alkemade JMR, Ihle F, Leemans R, Latour JB (2002). Assessing effects of forecasted climate change on the diversity and distribution of European higher plants for 2050. Global Change Biology 8: 390-407. - doi: 10.1046 /j.1354-1013.2001.00467.x

Barrows CW, Rotenberry JT, Allen MF (2010). Assessing sensitivity to climate change and drought variability of a sand dune endemic lizard. Biological Conservation 143: 731-736. doi: 10.1016/j.biocon.2009.12.013

Champion HG (1936). A preliminary survey of the forest types of India and Burma. In: "Indian Forest Records (New Series)". Vol i, no. 1, Government of India Press, New Delhi, India, pp.
286.

Craig BS (1991). The Capped Langur in Bangladesh: behavioural ecology and reproductive tactics. S Karger publisher, Basel, Switzerland, pp. 180. [online] URL: http://books.google.com/ books?id=CoacsVaaGMcC

Dawson TP, Jackson ST, House JI, Prentice IC, Mace GM (2011). Beyond predictions: biodiversity conservation in a changing climate. Science 332: 53-58. - doi: 10.1126/science.1200303

Dullinger S, Gattringer A, Thuiller W, Moser D, Zimmermann NE, Guisan A, Willner W, Plutzar C, Leitner M, Mang T, Caccianiga M, Dirnböck T, Ertl S, Fischer A, Lenoir J, Svenning J, Psomas A, Schmatz DR, Silc U, Vittoz P, Hülber K (2012). Extinction debt of high-mountain plants under twenty-first century climate change. Nature Climate Change 2: 619-622. - doi: 10.1038/nclimate 1514

Efron B, Stein C (1981). The jackknife estimate of variance. The Annals of Statistics 9 (3): 586596. - doi: 10.1214/aos/1176345462

Elith J, Graham CH, Anderson RP, Elith J, Graham $\mathrm{CH}$, Anderson RP, Dudik M, Ferrier S, Guisan A, Hijmans RJ, Huettmann F, Leathwick JR, Lehmann A, Li J, Lohmann LG, Loiselle BA, Manion G, Moritz C, Nakamura M, Nakazawa Y, Overton JMC, Peterson AT, Phillips SJ, Richardson KS, Scachetti-Pereira R, Schapire RE, Soberon J, Williams S, Wisz MS, Zimmermann NE (2006). Novel methods improve prediction of species' distributions from occurrence data. Ecography 29: 129-151. - doi: 10.1111/j.2006.0906-7590.0459 6.x

Elith J, Leathwick JR (2009). Species distribution models: ecological explanation and prediction across space and time. Annual Review of Ecology, Evolution and Systematics 40: 677-697. doi: 10.1146/annurev.ecolsys.110308.120159 Feeley KJ, Silman MR (2010). Land-use and climate change effects on population size and extinction risk of Andean plants. Global Change Biology 16: 3215-3222. - doi: 10.1111/j.1365-2486. 2010.02197.x

Franklin J (2009). Mapping species distributions: spatial inference and prediction. Cambridge University Press, Cambridge, UK, pp. 336.

Gray TNE, Chamnan H, Borey R, Collar NJ, Dolman PM (2007). Habitat preferences of a globally threatened bustard provide support for community based conservation in Cambodia. Biological Conservation 138: 341-350. - doi: 10.1016/j.biocon.2007.04.030

Guisan A, Thuiller W (2005). Predicting species distribution: offering more than simple habitat models. Ecology Letters 8: 993-1009. - doi: 10.1111/j.1461-0248.2005.00792.x

Hannah L, Midgley G, Millar D (2002). Climate change-integrated conservation strategies. Global Ecology and Biogeography 11: 485-495. doi: 10.1046/j.1466-822X.2002.00306.x

Hijmans RJ, Cameron SE, Parra JL, Jones PG, Jarvis A (2005). Very high resolution interpolated climate surfaces for global land areas. International Journal of Climatology 25: 1965 1978. - doi: 10.1002/joc.1276

Jain SK, Meenaa S, Gupta AP, Kushwaha M, Shaanker RU, Jaglan S, Bharate SB, Vishwakarma RA (2014). Dysoxylum binectariferum bark as a new source of anticancer drug camptothecin: bioactivity-guided isolation and LCMS-ba- 
sed quantification. Bioorganic and Medicinal Chemistry Letters 24: 3146-3149. - doi: 10.1016/j. bmcl.2014.05.001

Khan MS, Matiur RM, Arshad AM (2001). Red data book of vascular plants of Bangladesh. Bangladesh National Herbarium, Dhaka, Bangladesh, pp. 179.

Karjalainen E, Sarjala T, Raitio H (2010). Promoting human health through forests: overview and major challenges. Environmental Health and Preventive Medicine 15: 1-8. - doi: 10.1007/ s12199-008-0069-2

Lenoir J, Gegout JC, Marquet PA, Ruffray PD, Brisse $H$ (2008). A significant upward shift in plant species optimum elevation during the $20^{\text {th }}$ century. Science 320: 1768-1771. - doi: 10.1126/ science. 1156831

Meinshausen M, Smith SJ, Calvin K, Daniel JS, Kainuma MLT, Lamarque JF, Matsumoto K, Montzka SA, Raper SCB, Riahi K, Thomson A, Velders GJM, Van Vuuren DPP (2011). The RCP greenhouse gas concentrations and their extensions from 1765 to 2300 . Climate Change 109: 213-24. - doi: 10.1007/s10584-011-0156-z

NACOM (2003). Co-management of tropical forest resources of Bangladesh: secondary data collection for pilot protected areas: Lawachara National Park. Nature Conservation Management (NACOM), USAID/Bangladesh and Ministry of Environment and Forest, Government of Bangladesh, Dakha, Bangladesh, pp. 54.

NSP (2006). Protected areas of Bangladesh: a visitor's guide. Nishorgo Support Project (NSP), Dhaka, Bangladesh, pp. 41.

Oliver T, Hill JK, Thomas CD, Brerton T, Roy DB (2009). Change in habitat specificity of species at their climate change range boundaries. Ecology Letters 12: 1091-1102. - doi: 10.1111/j.1461-024 8.2009.01367.x

Parcha V, Gahlot M, Kaur J, Tomar Y (2004). A review on phytochemical and pharmacological studies of Dysoxylum species. Journal of Natural Remedies 4: 1-11. [online] URL: http:// www.informaticsjournals.org/index.php/jnr/arti cle/viewFile/390/390

Parmesan C, Yohe G (2003). A globally coherent fingerprint of climate change impacts across natural systems. Nature 421: 37-42. - doi: 10.1038/nature01286

Peng H, Mabberley DJ (2008). Dysoxylum Blume. Flora of China. Vol. 11 (Oxalidaceae through Aceraceae). Science Press, Beijing, China and Missouri Botanical Garden Press, St. Louis, MO, USA, pp. 50.

Peterson AT, Shaw J (2003). Lutzomyia vectors for cutaneous leishmaniasis in southern Brazil: ecological niche models, predicted geographic distribution, and climate change effects. International Journal of Parasitology 33: 919-931. doi: 10.1016/So020-7519(03)00094-8

Phillips SJ, Anderson RP, Schapire RE (2006). Maximum entropy modeling of species geographic distributions. Ecological Modelling 190: 231-259. - doi: 10.1016/j.ecolmodel.2005.03.026 Phillips SJ, Dudik M, Elith J, Graham CH, Lehmann A, Leathwick J, Ferrier S (2009). Sample selection bias and presence-only distribution models: implications for background and pseudo-absence data. Ecological Applications 19 (1): 181-197. - doi: 10.1890/07-2153.1

Riahi K, Gruebler A, Nakicenovic N (2007). Scenarios of long-term socio-economic and environmental development under climate stabilization. Technological Forecasting and Social Change 74 (7): 887-935. - doi: 10.1016/j.tech fore.2006.05.026

Shrestha UB, Bawa KS (2014). Impact of climate change on potential distribution of Chinese caterpillar fungus (Ophiocordyceps sinensis) in Nepal Himalaya. PLoS ONE 9: 1-11. - doi: 10.1371/ journal.pone.0106405

Sohel MSI, Mukul SA, Burkhard B (2015). Landscape's capacities to supply ecosystem services in Bangladesh: a mapping assessment for Lawachara National Park. Ecosystem Services 12: 128-135. - doi: 10.1016/j.ecoser.2014.11.015
Sohel MSI, Rana MP, Karim SMF, Akhter S (2010). Linking co-management, livelihood and forest conservation in protected area: a case study of wildlife sanctuary. International Journal of Ecological Economics and Statistics 16: 86-95. [online] URL: http://www.ceserp.com/ cp-jour/index.php?journal=ijees\&page=article\& op=view\&path[]=472

Thomas CD, Cameron A, Green RE, Bakkenes M, Beaumont LJ, Collingham YC, Erasmus BF, de Siqueira MF, Grainger A, Hannah L, Hughes L, Huntley B, van Jaarsveld AS, Midgley GF, Miles L, Ortega-Huerta MA, Townsend Peterson A, Phillips OL, Williams SE (2004). Extinction risk from climate change. Nature 427 (6970): 145148. - doi: 10.1038/nature02121

Trisurat Y, Rajendra P, Shrestha B, Kjelgren R (2011). Plant species vulnerability to climate change in peninsular Thailand. Applied Geography 31: 1106-1114. - doi: 10.1016/j.apgeog.2011. 02.007

Welk E, Schubert K, Hoffmann MH (2002). Present and potential distribution of invasive mustard (Alliara petiolata) in North America. Diversity and Distribution 8: 219-233. - doi: 10.1046/j. 1472-4642.2002.00144.x

Wise MA, Calvin KV, Thomson AM, Clarke LE, Bond-Lamberty B, Sands RD, Smith SJ, Janetos AC, Edmonds JA (2009). Implications of limiting $\mathrm{CO}_{2}$ concentrations for land use and energy. Science 324: 1183-1186. - doi: 10.1126/science.116 8475

Wiens JA, Stralberg D, Jongsomjit D, Howell CA, Snyder MA (2009). Niches, models, and climate change: assessing the assumptions and uncertainties. Proceedings of the National Academy of Sciences USA 106: 19729-19736. - doi: 10.1073/ pnas.0901639106

Yu D, Zhou L, Zhou W, Ding H, Wang Q, Wang Y, Wu X, Dai L (2011). Forest management in northeast China: history, problems, and challenges. Environmental Management 48: 11221135. - doi: 10.1007/s00267-011-9633-4 